\title{
West of the Rockies
}

\section{Speaker's Corner}

\section{A little conversation: reflections of a hospital volunteer}

Hospitals in general are not cherished places. Hospitals exude a cold, bleak, and awful feeling. They are easy to dislike. But, I like hospitals. They are the places where I have grown up, waited expectantly for my father to finish one of his many shifts, celebrated birthdays, and most of all, been touched by the most amazing feeling that this world has brought forth.

I do volunteer work at Cedars-Sinai Medical Center in Los Angeles, California; I aspire to be a physician someday. From a distance, the Center is an enormous group of sterile-looking buildings. On entering, there is a strangeness in the air. Even to this day, I hesitate venturing into the "inner depths" of the hospital, such as the ICUs, without the company of another soul. The never-ceasing activity of patients' monitors makes me feel as if I'm being watched. I find myself checking my backside, hoping no one is present, yet

\section{All that they yearn for is}

\section{some personal attention-}

\section{a brief conversation-that}

\section{will remove them from their}

\section{aloneness}

also hoping someone is. Nevertheless, this gargantuan place has become less intimidating with time. Indeed, I now find myself at peace within it. A good thing too, for soon it will be my place of work, rather, my life.

The people I meet as a hospital volunteer usually have a terrible illness. Some may get better, some will certainly die. In all likelihood, they are scared, and every emotion that they have ever experienced is racing inside of them. For the majority, all that they yearn for is some personal attention-a brief conversation-that will momentarily remove them from their aloneness in their downward spiraling world. People too often say, "talk is cheap." But the spoken word has no monetary value; it is materially useless. Yet, therein lies its value.

It is easy to offer a few supportive and reassuring words, words with value, to someone who is consumed with a fearful future, and possible imminent mortality. Why do we not act in this manner more often? Perhaps our own lives are too busy, and too important, to take a few minutes to ease the mind of a person in need. Or, even though we realize that death is a part of all of our lives, it still creates uneasiness to think of losing a loved one through death. It is simply easier not to become involved, not to interact.

In my experience, from the moment that I enter a patient's room and begin a conversation with them, I can feel their gloom lifting. Somehow, my talking with them allows their medical problems to temporarily vanish. The talk seems natural, as though we're on a street corner, and we were old friends being reacquainted. We are intrigued by each other. Everything around this patient and me somehow ties us together. Physically, we share the same air, space, and time during the interaction, but the gravity of the situation causes any other differences to dissipate, and the commonness of our own humanity shows through. The two of us bond, forming a special mental unity that momentarily replaces their anxiety.

Each individual patient's situation is different and cannot be recreated; however, each situation requires the same thing - a little communication. When in the presence of these patients, I feel different. The occasion allows me to venture inside each person's soul and I am uplifted to see the joy it brings to the patients. If I can ease someone's overall tensions, temporarily take their minds off the severe pain they feel, or the doom that they see ahead, I may be doing my part to make this lifetime better. Life is precious; it is momentary; it is too short.

Brian W Ault, age 17

Los Angeles, California

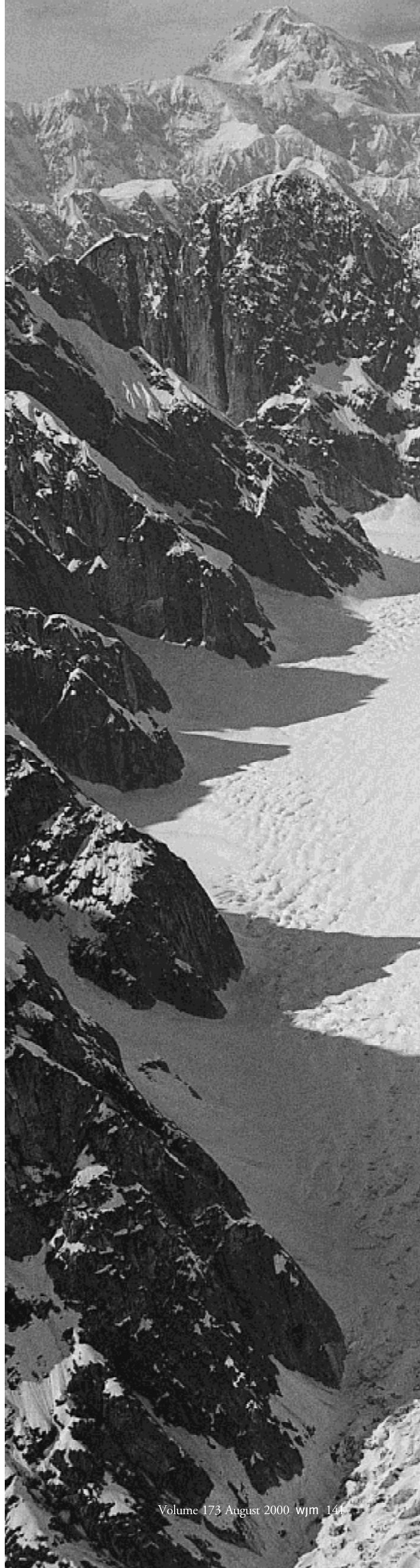

